\title{
Study on the Influence of Rainfall Infiltration on the High rock Slope of Open-pit Mine Stability using a New Nonlinear Strength Reduction Method
}

\section{Tianbai Zhou}

China Coal Research Institute (China)

Lingfan Zhang ( $\nabla$ zhanglf@student.cumtb.edu.cn )

China University of Mining and Technology

Jian Cheng

China Coal Research Institute (China)

Jianming Wang

Ansteel Beijing Research Institute

Xiaoyu Zhang

China Coal Research Institute (China)

Maoyuan Li

Housing and Urban Rural Development Bureau

\section{Research Article}

Keywords: High rock slope, A new nonlinear strength reduction method, Rainfall infiltration, Stability analysis

Posted Date: September 24th, 2021

DOI: https://doi.org/10.21203/rs.3.rs-914757/v1

License: (c) (i) This work is licensed under a Creative Commons Attribution 4.0 International License.

Read Full License 


\title{
Study on the influence of rainfall infiltration on the high rock slope of open-pit mine stability using a new nonlinear strength reduction
}

\author{
method \\ Tianbai Zhou ${ }^{1,2}$, Lingfan Zhang ${ }^{3,4^{*}}$, Jian Cheng ${ }^{1,2}$, Jianming Wang ${ }^{5}$, Xiaoyu Zhang ${ }^{1,2}$, \\ Maoyuan $\mathrm{Li}^{6}$ \\ ${ }^{1}$ Research Institute of Mine Big Data, China Coal Research Institute, Beijing 100013, China \\ ${ }^{2}$ State Key Laboratory of Coal Mining and Clean Utilization, Beijing 100013, China \\ ${ }^{3}$ School of Mechanics and Civil Engineering, China University of Mining and Technology, Beijing 100083, China \\ ${ }^{4}$ Institute of Geotechnical Engineering, RWTH Aachen University, Mies-van-der-Rohe-Str. 1, 52074, Aachen, Germany \\ ${ }^{5}$ Ansteel Beijing Research Institute, Beijing 102209, China \\ ${ }^{6}$ Housing and Urban Rural Development Bureau, Qionglai City, Sichuan 611500, China \\ ${ }^{*}$ Correspondence: zhanglf@student.cumtb.edu.cn (L.Z.)
}

\begin{abstract}
Due to long-term mining, a series of high and steep rock slopes have been formed in the open-pit mine. For high rock slopes, rainfall infiltration is the main cause of landslide. Therefore, the stability analysis of high rock slope under rainfall has become a key issue in the open-pit mine engineering. In this work, aiming at the high stress condition of high rock slope, the instantaneous internal friction angle and instantaneous cohesion of rock mass under different stress states are deduced, and the a nonlinear strength reduction method for high rock slope is established according to the relationship between normal stress and shear stress of rock mass under the Hoke-Brown criterion. The numerical calculation results show that the factor of safety (FOS) for high rock slope calculated by the proposed method is more reasonable. Taking the southwest slope of Dagushan Iron Mine as the research background, the safety factors of high rock slope under different rainfall conditions are calculated by COMSOL Multiphysics. And the stability analysis of high rock slope in open-pit mine under rainfall are carried out.
\end{abstract}

Key words: High rock slope; A new nonlinear strength reduction method; Rainfall infiltration; Stability analysis

\section{Introduction}

As China's "the belt and road" strategy is implemented, a new upsurge in construction of hydropower stations, mines, highways and railways in China is in the making. These projects will inevitably face high and steep slope problems. High rock slope has the characteristics of large scale, complex geological conditions and high geostress, and its stability is the key for the engineering construction. According to the statistics of landslides in open-pit mines in China in recent 30 years, there are more than ten landslides with large scale, which lead to serious economic and personnel losses. It is found that most of the large-scale landslides in these mines are directly related to the action of water, and most of them occur in the rainy season ${ }^{[1-4]}$. The direct reason is that the rainfall infiltration forms a transient saturation zone in the slope

\footnotetext{
* Corresponding authors.

E-mail address: zhanglf@student.cumtb.edu.cn (L.Z.)
} 
body, which reduces the safety factor. Therefore, the stability analysis of high rock slope under rainfall has become a key issue in the open-pit mine engineering ${ }^{[5,6]}$.

Rainfall has a greater influence on slope stability. The shear strength of the weak surface will be reduced by water immersion and infiltration, leading to an increase in sliding force, which will result in slope damage. Rainfall is the main factor that induces landslides on slopes, and the study of rainfall infiltration theory has been one of the research focuses in the field of slope engineering. Rainfall infiltration will cause changes in the seepage field of slope rock, which will change the stress field and eventually lead to slope instability and damage. The evolution of slope seepage field and slope seepage characteristics under rainfall infiltration are the basis for studying the impact of rainfall infiltration on slope stability ${ }^{[7,8]}$. Several studies have been conducted for rainfall infiltration-induced slope landslides. Rezaur et al. ${ }^{[9]}$ studied the influence of rainfall infiltration on the slope stability when the saturated permeability coefficient changes. Alonso et al. [10] considered the influence of rainfall duration, rainfall intensity, soil type, shape of soil water characteristic curve and soil permeability on slope stability. Zhang et al. ${ }^{[11]}$ studied the influence of different water characteristic curve shapes on the pore-water pressure distribution of slope. Rahimi et al. ${ }^{[12]}$ studied the influence of water characteristic curve parameters on slope stability with different drainage effects.

In recent decades, with the rapid development of computer technology, numerical analysis method has been widely used in slope engineering ${ }^{[13-16]}$. On this basis, the strength reduction method has gradually become the main method to study the stability of rock slope. Compared with other methods, the rock stressstrain relationship could be considered by this method and that obtain the critical sliding surface and the minimum safety factor without assuming the shape and position of the sliding surface ${ }^{[17-20]}$. In the meantime, the progressive failure process of slope could be simulated by the strength reduction method. The generalized Hoek-Brown has been proved to be effective in the empirical calculation of shear strength of rock mass ${ }^{[21}$, ${ }^{22]}$. Therefore, it is necessary to combine the strength reduction method with Hoek-Brown criterion ${ }^{[23-25]}$. Many researchers have worked on the study and implementation of strength reduction method (SRM) with the nonlinear generalized Hoek-Brown (GHB) criterion, referred to as the nonlinear strength reduction method (NSRM ${ }^{[26-29]}$. Hammah et al. ${ }^{[30]}$ proposed a global GHB shear strength reduction method by lowering the GHB shear envelopes. Benz et al. ${ }^{[31]}$ established a mathematical expression for the relationship between the GHB criterion and the MC criterion, and used the MC criterion reduction factors to determine the strength reduction based on GHB criterion. Wu et al. ${ }^{[32]}$ concluded that for intact rock, only uniaxial compressive strength and rock hardness should be used as strength indicators for GHB strength reduction. Fu et al. ${ }^{[33]}$ introduced the Mohr-Coulomb instantaneous friction angle as a variable, used the instantaneous Moore-Coulomb friction angle and cohesive strength to describe the shear strength of rock mass, and proposed a nonlinear shear strength reduction technique for slope stability calculations. Sun et al. ${ }^{[34]}$ calculated the factor of safety (FOS) by combining slope geometric parameters, rock mass property parameters and GHB parameters, and proposed a simplified method to realize nonlinear strength reduction based on GHB criterion. In summary, the nonlinear strength reduction methods (NSRM) include: (1) linearization method and local linearization method of the nonlinear strength criterion; (2) the global reduction of GHB envelopes; (3) the direct reduction of GHB parameters. Considering the calculation accuracy and efficiency, these above methods may be applicable to the slopes under different conditions. For high rock slope, the high stress state of rock mass is the most critical factor for strength reduction. Therefore, a nonlinear strength reduction method considering high stress state should be proposed for the FOS calculation of high rock slope.

These knowledge gaps are seen as the main objectives in this work of stability analysis on the high rock 
slope. Aiming at the high stress of high rock slope, the instantaneous internal friction angle and instantaneous cohesion of rock mass under different stress states are deduced, and the new nonlinear strength reduction method for high rock slope is established according to the relationship between normal stress and shear stress of rock mass under the Hoke-Brown criterion. Taking the southwest slope of Dagushan Iron Mine as the research background, the safety factors of high rock slope under different rainfall conditions are calculated by the proposed nonlinear strength reduction method on COMSOL Multiphysics. The influence of rainfall infiltration on the stability of high rock slope in open-pit mine is analyzed.

\section{A new nonlinear strength reduction method}

\subsection{Hoek-Brown yield criterion}

Hoek-Brown (HB) strength criterion is an empirical formula of rock failure based on the theoretical research results of rock mechanics by evert Hoek and E.T. Brown. They have analyzed a large number of engineering field data. The theory scientifically sums up a large number of in-situ test results, solves many practical engineering problems, and is widely used in open-pit mining and slope engineering.

Hoek et al. ${ }^{[37]}$ introduced the geological strength index GSI and disturbance coefficient $D$ of the rock mass into the theory. The modified generalized HB expression is as follows:

$$
\sigma_{1}=\sigma_{3}+\sigma_{c i}\left(m_{b} \frac{\sigma_{3}}{\sigma_{c i}}+s\right)^{\alpha}
$$

Where $\sigma_{1}$ and $\sigma_{3}$ are the maximum and minimum principal stresses when the rock mass yields; $\sigma_{c i}$ is the uniaxial compressive strength of the complete rock; $m_{b}, s$ and $\alpha$ are the characteristic parameters of the rock mass.

$m_{b}, s$ and $\alpha$ can be given as functions related to $G S I$ and disturbance coefficient $D$ of rock mass:

$$
\begin{gathered}
m_{b}=m_{i} \exp \left(\frac{G S I-100}{28-14 D}\right) \\
s=\exp \left(\frac{G S I-100}{9-3 D}\right) \\
\alpha=\frac{1}{2}+\frac{1}{6}\left(e^{-G S I / 15}-e^{-20 / 3}\right)
\end{gathered}
$$

Where $m_{i}$ is Hoek Brown constant of complete rock; GSI is geological strength index of rock mass, which is selected according to rock mass structure and surface characteristics of structural plane; $D$ is disturbance coefficient, which is 1.0 for conventional blasting, 0.7 for mechanical excavation and $0.8-0.9$ for controlled blasting.

\subsection{Equivalent Mohr-Coulomb strength parameters}

Because most of the geotechnical engineering software is still based on Mohor-Coulomb (MC) failure criterion, few has been studied on non-linear shear strength reduction techniques ${ }^{[35-40]}$. It is necessary to determine the cohesion and internal friction angle of rock mass by HB criterion. HB criterion is non-linear, while MC criterion is linear, so cohesion and internal friction angle cannot be calculated directly [41-45]. Therefore, the strength curve of HB criterion is fitted as equivalent MC straight line to obtain cohesion and internal friction angle of rock mass, as shown in Figure 1. 


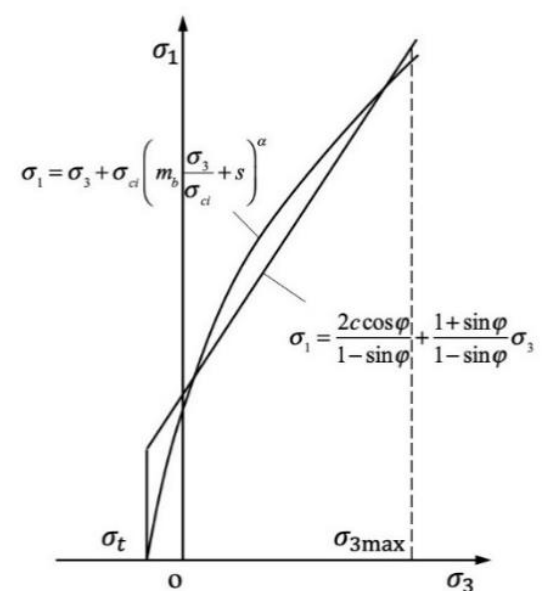

Fig. 1 Relationships between $\mathrm{HB}$ and equivalent MC criteria

In the fitting process, the upper and lower difference areas of $\mathrm{MC}$ straight line are balanced to obtain the equivalent $\mathrm{MC}$ parameters.

$$
\begin{gathered}
\varphi=\sin ^{-1}\left[\frac{6 a m_{b}\left(s+m_{b} \sigma_{3 n}\right)^{\alpha-1}}{2(1+\alpha)(2+\alpha)+6 a m_{b}\left(s+m_{b} \sigma_{3 n}\right)^{\alpha-1}}\right] \\
c=\frac{\sigma_{c}\left[(1+2 \alpha) s+(1-\alpha) m_{b} \sigma_{3 n}\right]\left(s+m_{b} \sigma_{3 n}\right)^{\alpha-1}}{(1+\alpha)(2+\alpha) \sqrt{1+\left[6 \alpha m_{b}\left(s+m_{b} \sigma_{3 n}\right)^{\alpha-1}\right] /[(1+\alpha)(2+\alpha)]}} \\
\sigma_{c m}=\sigma_{c i} \frac{\left[m_{b}+4 s-\alpha\left(m_{b}-8 s\right)\right]\left(m_{b} / 4+s\right)^{\alpha-1}}{2(1+\alpha)(2+\alpha)}
\end{gathered}
$$

According to the actual situation of slope engineering, Hoke et al. made specific provisions for the parameters in Formula (5) - Formula (7):

$$
\begin{gathered}
\frac{\sigma_{3 \max }}{\sigma_{c m}}=0.72\left(\frac{1000 \sigma_{c m}}{\gamma H}\right)^{-0.91} \\
\sigma_{3 n}=\frac{\sigma_{3 \max }}{\sigma_{c i}}
\end{gathered}
$$

Where $\sigma_{\mathrm{cm}}$ is the compressive strength of rock mass, $\sigma_{3 \max }$ is the maximum confining pressure, $H$ is the height of slope and $\gamma$ is the weight of rock mass.

As shown in Figure 2, in the coordinate space with normal stress $\sigma$ as the horizontal axis and shear stress $\tau$ as the vertical axis, the equivalent MC strength envelope curve is a straight line and HB strength envelope is a kinked line. The instantaneous cohesion $c_{i}$ and internal friction angle $\varphi_{i}$ can be obtained by making a tangent line on the HB strength envelope curve. ${ }^{[33,35]}$ It can be seen from the Figure 2 that with the increase of stress, the cohesion $c_{i}$ increases gradually, then it will be equal to the equivalent cohesion at a certain stress, while the internal friction angle $\varphi_{i}$ decreases gradually, then it will also be equal to the internal friction.

In slope engineering, the stress is relatively small in the shallow part of the slope as shown in point 1 in Figure 2, the cohesion and internal friction angle can be $C_{1}$ and $\varphi_{1}$ by tangent line, $C_{1}$ is smaller than $C$, and $\varphi_{1}$ is larger than $\varphi$. However, in the deep part of the slope, the stress is relatively large as shown in point 2 in Figure 2, the cohesion and internal friction angle can be obtained by tangent line, which are $C_{2}$ and $\varphi_{2}$ 
respectively, $C_{2}$ is larger than $C$, and $\varphi_{2}$ is less than $\varphi$.

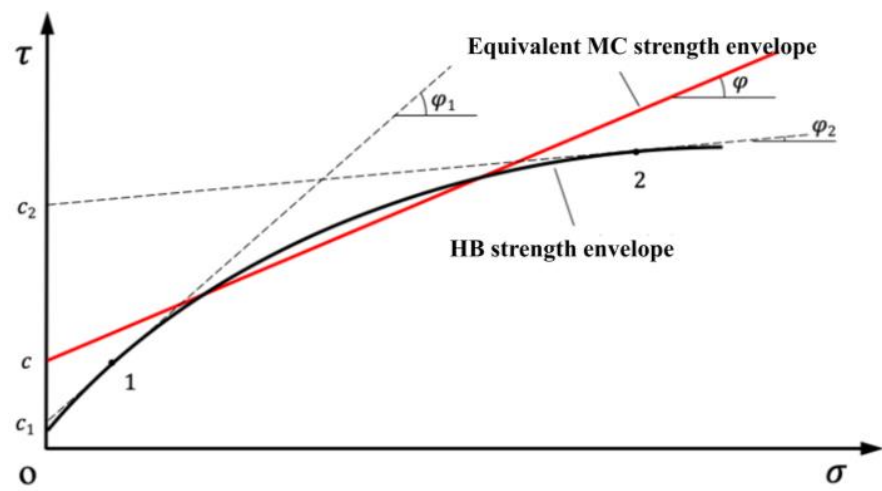

Fig. 2 The relationship between the equivalent MC strength envelope curve and HB strength envelope curve

Therefore, in view of the high stress characteristics of high rock slope, the establishment of the relationship between cohesion, internal friction angle and minimum principal stress is the key of slope strength reduction calculation.

\subsection{Nonlinear strength reduction method}

The equivalent MC strength parameters are fitted in the range of $\sigma_{t}<\sigma_{3}<\sigma_{3 \max }$. When the minimum principal stress is small, the calculated strength parameters are relatively accurate, but the larger the minimum principal stress is, the lower the calculation accuracy is. Because of the high and steep rock slope in open pit, it is necessary to determine the strength parameters of rock mass in case of large stress.

Under the condition of complex stress, the stress state of yield point in rock mass can be represented by limit Mohr circle on the coordinate space with normal stress $\sigma$ as horizontal axis and shear stress $\tau$ as vertical axis. Whether the strength envelope is a straight or kinked line, only one point of the limit Mohr circle is tangent to the envelope curve, as shown in Figure 3.

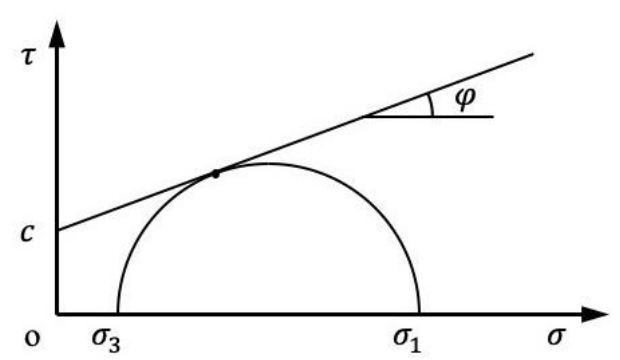

(a) Straight envelope curve

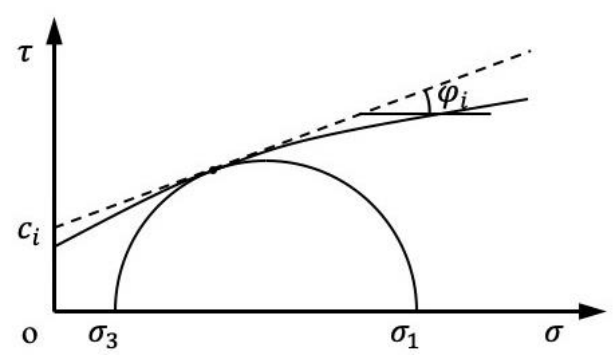

(b) Kinked envelope curve

Fig.3 Relationships between the Mohr circle and the damage envelope

The cohesion and internal friction angle corresponding to any point on the HB strength envelope curve are expressed by $c_{i}$ and $\varphi_{i}$ respectively. The normal stress $\sigma$ and shear stress $\tau$ on this point can be expressed by MC theory as follows:

$$
\begin{gathered}
\sigma=\frac{\sigma_{1}+\sigma_{3}}{2}-\frac{\sigma_{1}-\sigma_{3}}{2} \sin \varphi_{i} \\
\tau=\frac{\sigma_{1}-\sigma_{3}}{2} \cos \varphi_{i}
\end{gathered}
$$

The generalized HB expression Formula (1) is substituted into Formula (10) and Formula (11) yields: 


$$
\begin{gathered}
\sigma=\frac{1-\sin \varphi_{i}}{2} \sigma_{c i}\left(m_{b} \frac{\sigma_{3}}{\sigma_{c i}}+s\right)^{\alpha}+\sigma_{3} \\
\tau=\frac{\cos \varphi_{i}}{2} \sigma_{c i}\left(m_{b} \frac{\sigma_{3}}{\sigma_{c i}}+s\right)^{\alpha}
\end{gathered}
$$

For HB failure criterion, because the failure envelope curve is a kinked line, $\varphi_{i}$ changes with the change of minimum principal stress state, that is, $\varphi_{i}=\varphi\left(\sigma_{3}\right)$.

Taking the derivative of Formula (12) and Formula (13) with respect to $\sigma_{3}$ yields:

$$
\begin{gathered}
\frac{\mathrm{d} \sigma}{\mathrm{d} \sigma_{3}}=-\frac{\cos \varphi_{i}}{2} \frac{\mathrm{d} \varphi_{i}}{\mathrm{~d} \sigma_{3}} \sigma_{c i}\left(m_{b} \frac{\sigma_{3}}{\sigma_{c i}}+s\right)^{\alpha}+\frac{1-\sin \varphi_{i}}{2} \alpha m_{b}\left(m_{b} \frac{\sigma_{3}}{\sigma_{c i}}+s\right)^{\alpha-1}+1 \\
\frac{\mathrm{d} \tau}{\mathrm{d} \sigma_{3}}=-\frac{\sin \varphi_{i}}{2} \frac{\mathrm{d} \varphi_{i}}{\mathrm{~d} \sigma_{3}} \sigma_{c i}\left(m_{b} \frac{\sigma_{3}}{\sigma_{c i}}+s\right)^{\alpha}+\frac{\cos \varphi_{i}}{2} \alpha m_{b}\left(m_{b} \frac{\sigma_{3}}{\sigma_{c i}}+s\right)^{\alpha-1}
\end{gathered}
$$

On the $\tau$ - $\sigma$ coordinate space:

$$
\tan \varphi_{i}=\frac{\mathrm{d} \tau}{\mathrm{d} \sigma}=\frac{\mathrm{d} \tau}{\mathrm{d} \sigma_{3}} / \frac{\mathrm{d} \sigma}{\mathrm{d} \sigma_{3}}
$$

Substituting Formula (14) and Formula (15) into Formula (16) and simplifying yields:

$$
\begin{gathered}
\varphi_{i}=\sin ^{-1}\left(\frac{\alpha m_{b} A^{\alpha-1}}{2+\alpha m_{b} A^{\alpha-1}}\right) \\
A=m_{b} \frac{\sigma_{3}}{\sigma_{c i}}+s
\end{gathered}
$$

The equation of MC failure envelope curve on $\tau$ - $\sigma$ coordinate space can be expressed as follows:

$$
\tau=c_{i}+\sigma \tan \varphi_{i}
$$

Substituting Formula (12), (13) and (17) into Formula (18) yields:

$$
c_{i}=\frac{2 \sigma_{c i} A^{\alpha}+\alpha m_{b} \sigma_{c i} A^{2 \alpha-1}}{2\left(2+\alpha m_{b} A^{\alpha-1}\right) \sqrt{1+\alpha m_{b} A^{\alpha-1}}}-\frac{\alpha m_{b} A^{\alpha-1}}{2 \sqrt{1+\alpha m_{b} A^{\alpha-1}}} \sigma_{3}
$$

It can be seen from Formula (17) and Formula (19) that the values of $c_{i}$ and $\varphi_{i}$ are related to the minimum principal stress in the limit state, the HB characteristic parameters of rock mass and the uniaxial compressive strength of rock. The HB characteristic parameters and uniaxial compressive strength of HB rock mass are known. The stress state of the slope rock mass is calculated by the finite element method, and the minimum principal stress $\sigma_{\mathrm{e} 3}$ is obtained. As shown in Figure 4, $c_{i}$ and $\varphi_{i}$ of each point in the rock mass can be obtained by substituting $\sigma_{3}=\sigma_{\mathrm{e} 3}$. 


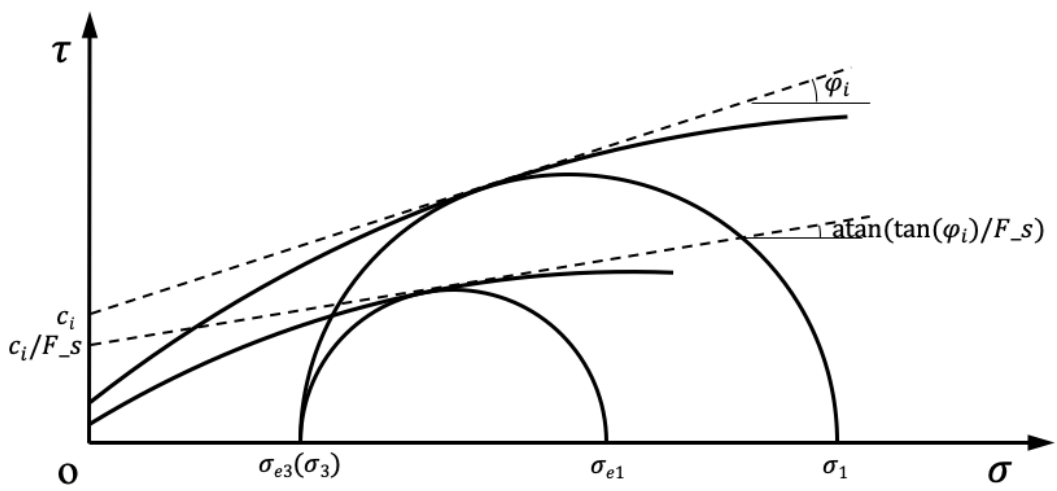

Fig. 4 Reduction calculation sketch

\subsection{Implementation of nonlinear strength reduction method based on HB criterion}

Using COMSOL multiphysics software, this paper embeds the calculation method of instantaneous equivalent $\mathrm{MC}$ strength parameters into the strength reduction calculation program, so as to realize the application of HB criterion finite element strength reduction method in slope stability analysis. The calculation flow is shown in Figure 5. The calculation process consists of three parts: establishing models, parameters calculation and strength reduction.

Step 1. The solution area is determined according to the geometric parameters of slope, and the material parameters of rock mass are inputted. Mesh generation is carried out according to certain laws in the solution area, and the triangular element with three nodes is selected. The loading and boundary conditions are set, and the initial slope stability can be calculated.

Step 2. The initial value of reduction coefficient $\mathrm{K}$ is set to 1 , the stress state of slope rock mass is calculated by FEM, and the minimum principal stress of slope can be obtained. The instantaneous cohesion $c_{i}$ and internal friction angle $\varphi_{i}$ of each element of the slope model are calculated according to Formulas (17) and (19).

Step3. According to the reduction coefficient $\mathrm{K}, c_{i}$ and $\varphi_{i}$ are reduced. Judge whether the slope model converges. If the model converges, end the calculation and output the reduction coefficient $\mathrm{K}$. Otherwise, the parameter $c_{i}$ and $\varphi_{i}$ are reduced by increasing the reduction coefficient $\mathrm{K}$, and the calculation procedure in Steps 2-3 is repeated until slope failure occurs. 


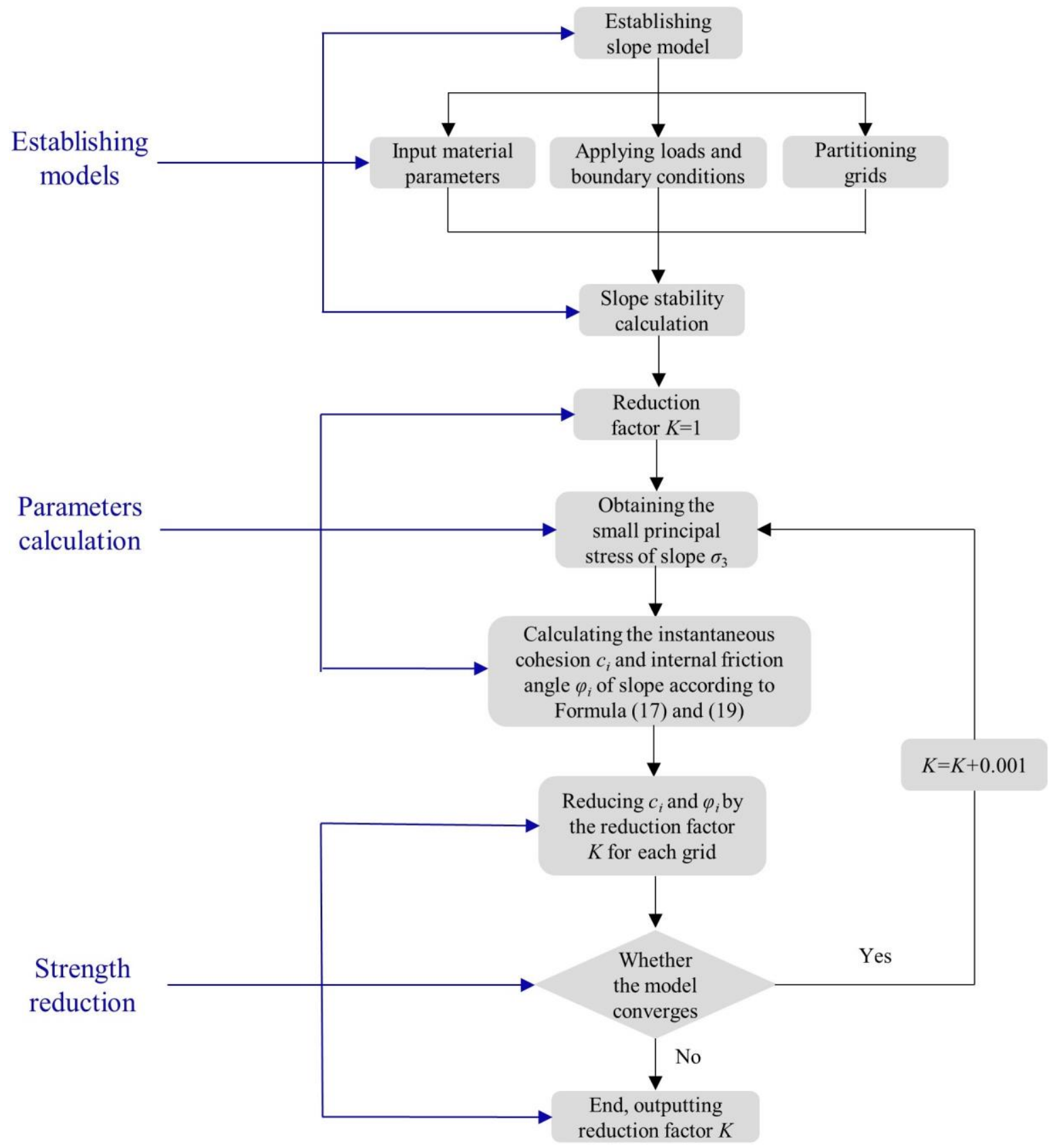

Fig. 5 Flow chart for calculation of strength reduction method

\section{Case study and verification}

In order to verify the effectiveness of the new nonlinear strength reduction method proposed in the previous section, a simple slope model is established using COMSOL multiphysics software, with a slope height of $200 \mathrm{~m}$ and a slope gradient of 1:1, as shown in Figure 6. The model boundary conditions are set as followed: the left and right boundaries of the slope are set as roller support constraints, and the bottom boundary is set as fixed constraints. Case A adopts the new nonlinear strength reduction method proposed in the previous section, and case $\mathrm{B}$ adopts the equivalent $\mathrm{MC}$ strength parameter reduction. 


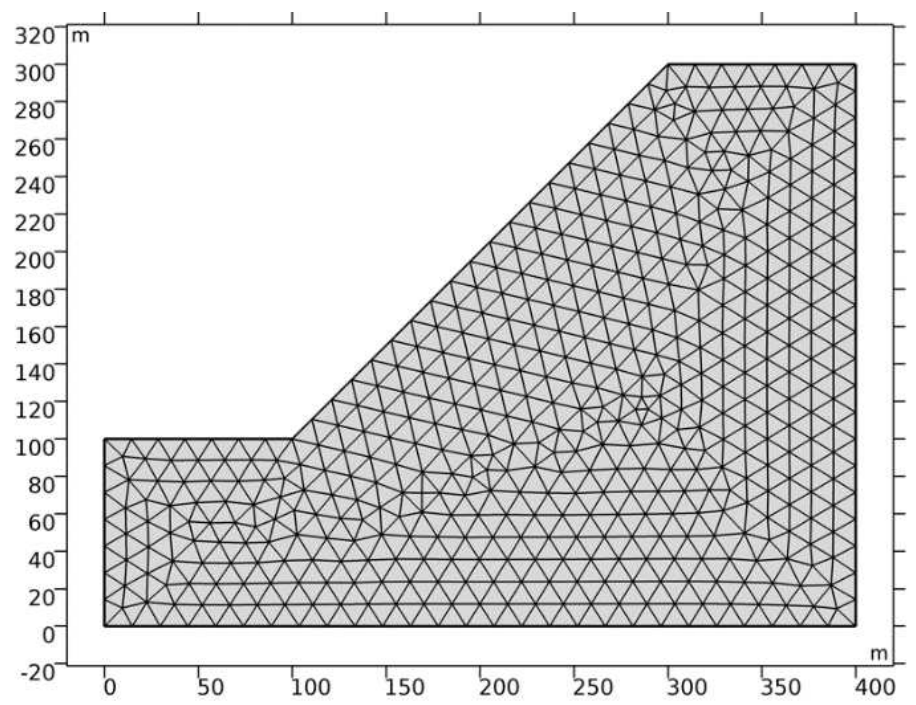

Fig. 6 Slope model establishment and grid division

The strength parameters of slope rock mass are based on the data in Table 1, and the strength parameters of equivalent MC criterion are calculated according to Formula (5) and Formula (6). The stress state in the slope is calculated using COMSOL multiphysics software, and the calculation result of the minimum principal stress $\sigma_{3}$ is shown in Figure 7.

Tab. 1 Strength parameter

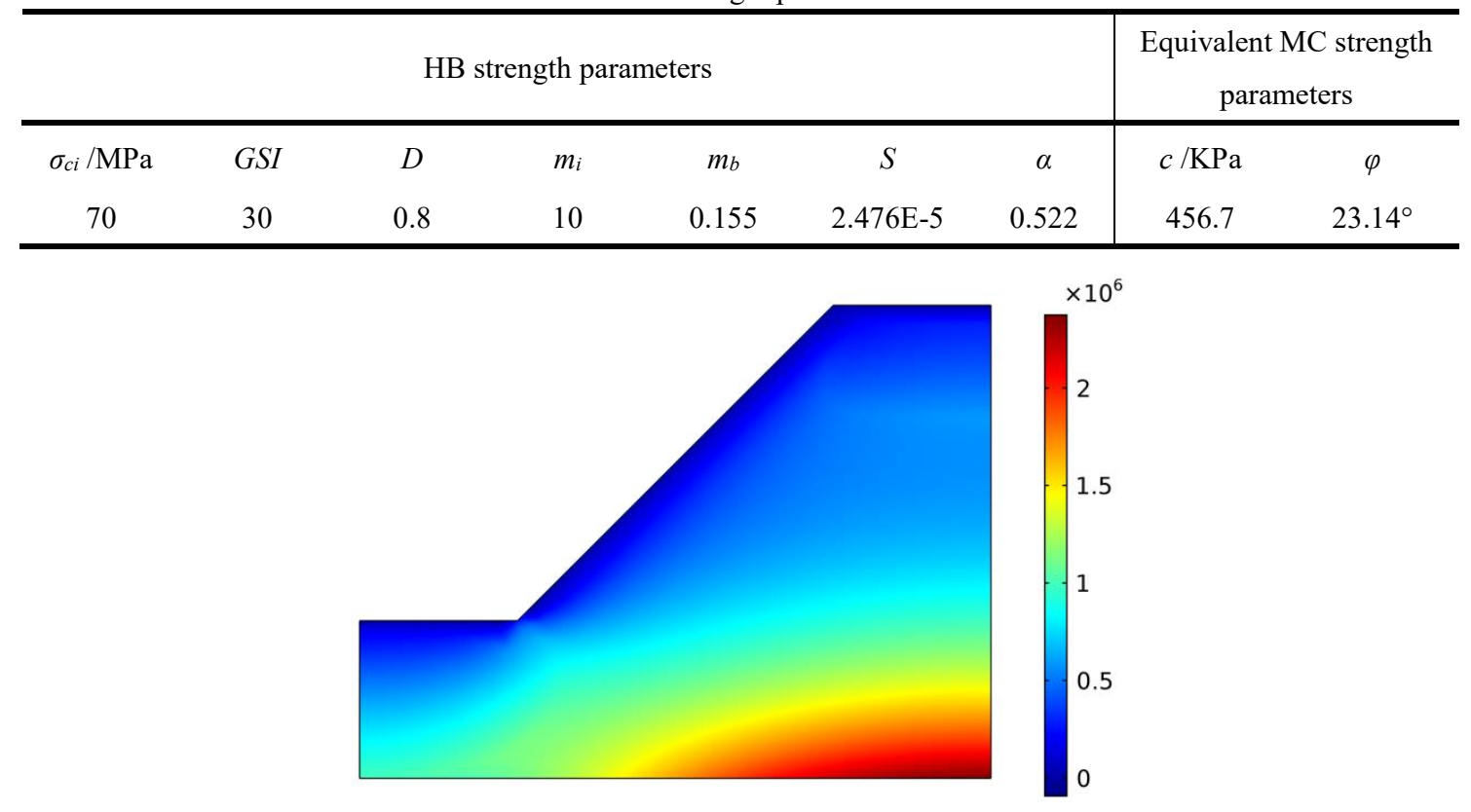

Fig. 7 Minimum principal stress $\left(\mathrm{N} / \mathrm{m}^{2}\right)$

The calculated minimum principal stress $\sigma_{3}$ and $\mathrm{HB}$ strength parameters are substituted into Formula (17) and Formula (19) to obtain the non-linear MC strength parameters $c_{i}$ and $\varphi_{i}$ in the slope. The calculation results are shown in Figure 8. 


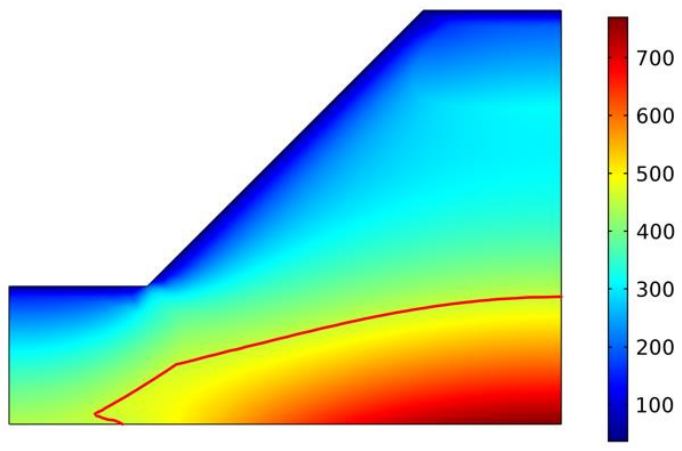

(a) Cohesion $/ \mathrm{KPa}$

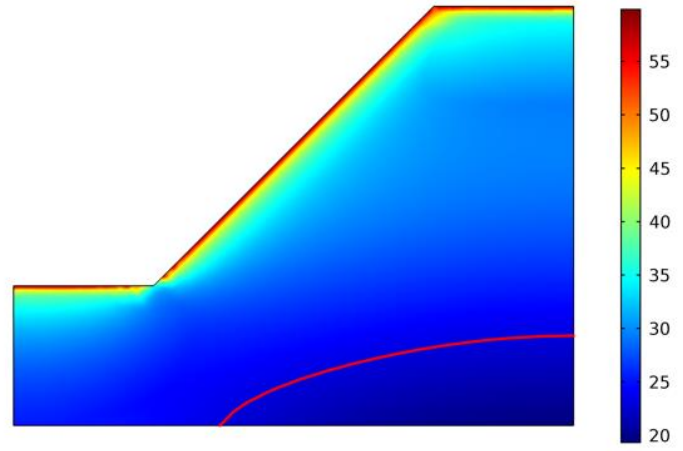

(b) Internal friction angle $/{ }^{\circ}$

Fig. 8 The distribution of cohesion and internal friction angle

From the calculation results shown in Figure 8, it can be seen that the cohesion of case A decreases gradually from the inside out, and the cohesion at the upper part is less than the equivalent cohesion, while the change of internal friction angle is opposite to the cohesion, they are non-linear.

For the case $\mathrm{A}$, the strength reduction calculation is carried out by using the nonlinear $\mathrm{MC}$ strength parameters $c_{i}$ and $\varphi_{i}$ based on HB criterion. The safety factor of the slope is 1.24 . For the case B, the equivalent $\mathrm{MC}$ criterion strength parameters are directly used for strength reduction calculation. The safety factor of the slope is 1.30. The plastic strain distribution and total displacement diagram of the two cases in the limit state are shown in Figure 9.

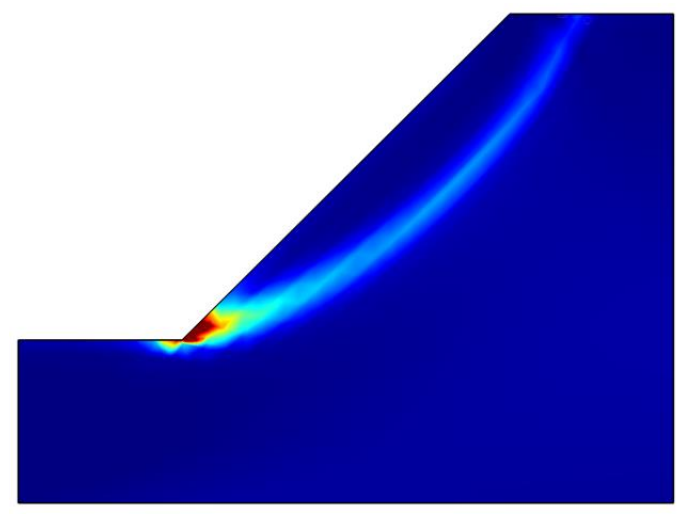

(a) The plastic strain distribution of case $\mathrm{A}$

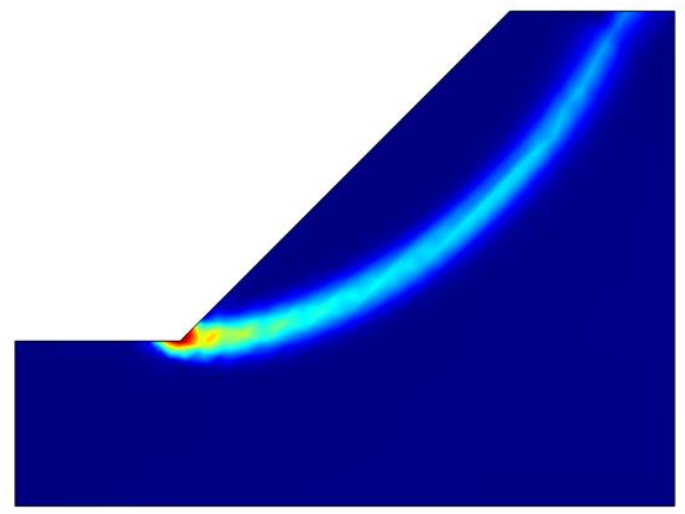

(c) The plastic strain distribution of case B

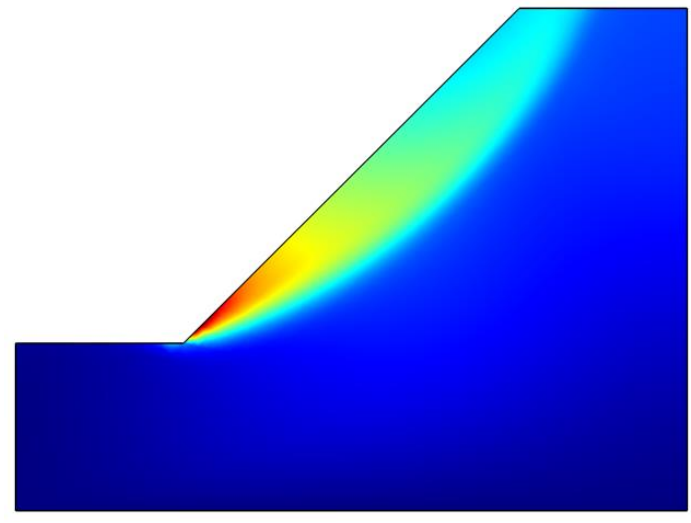

(b) The total displacement of case A

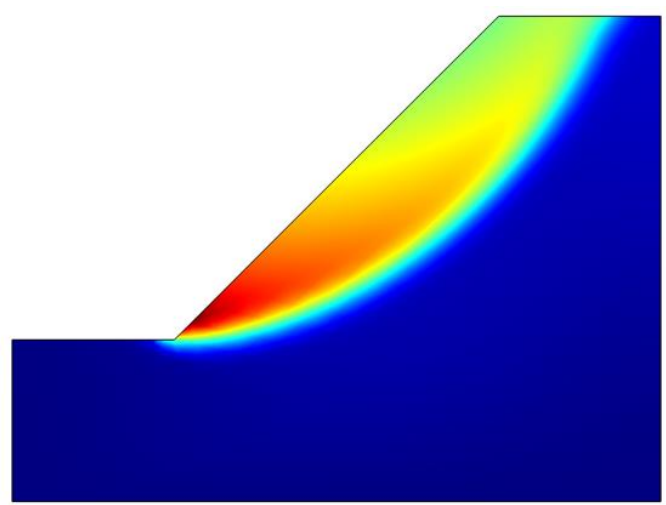

(d) The total displacement of case B

Fig. 9 The plastic strain distribution and total displacement. 
It can be clearly observed from Figure 9 that the potential sliding surface of case $\mathrm{A}$ is closer to the slope surface than case B, and the landslide body of case A is smaller than case B. And the factor of safety (FOS) calculated in case A is less than that calculated in case B and the stability of slope in case B is overestimated. Obviously, the simulation results of case A are more closer to the actual situation. Therefore, the proposed nonlinear strength reduction method is more reasonable in numerical calculation.

The equivalent MC strength parameters are estimated by fitting, and their accuracy depends on the range of the minimum principal stress. However, the nonlinear strength parameters derived in the previous section are related to the minimum principal stress, the characteristic parameters of HB rock mass and the uniaxial compressive strength of rock. For the strength reduction of high rock slope in open pit mines, the stress state should be considered to propose the reduction method. The results show that it is more reasonable to simulate and calculate high rock slope with the proposed nonlinear strength reduction method, which can be effectively applied to the stability analysis of high rock slope.

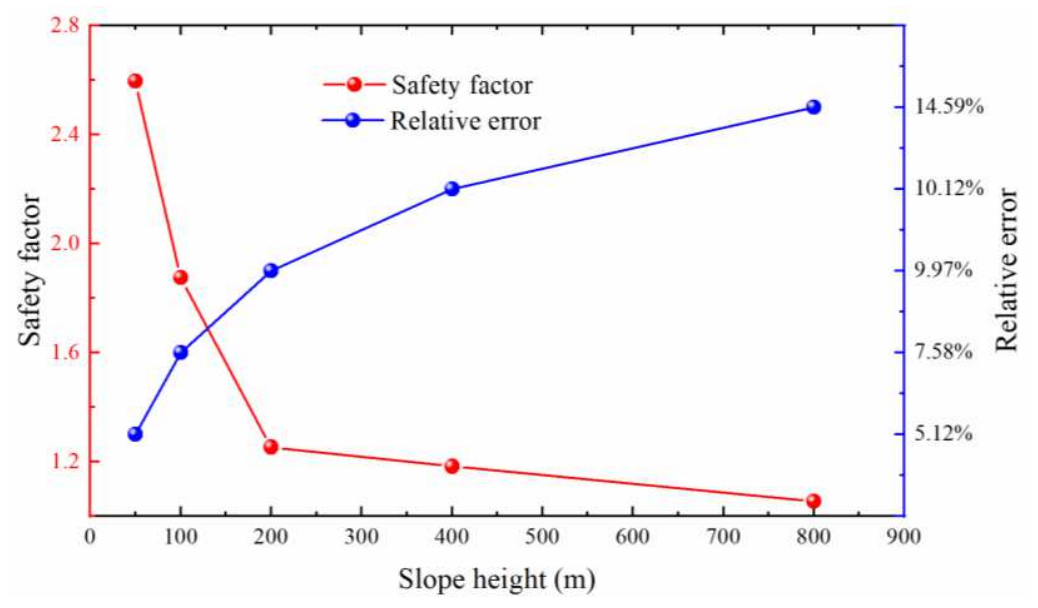

Fig. 10 Relation curve between slope height and safety factor

In order to further explore the rationality and practicability of the proposed nonlinear strength reduction method for the stability calculation of high rock slope, the authors established rock slope with different height in the COMSOL multiphysics software, and analyzed the difference of the factor of safety (FOS) calculated using the two methods with the change of slope height, as shown in Figure 10.

Figure 10 shows the relationship between safety factor and slope height. It can be seen from the figure that as the height increases, the safety factor of the whole slope decreases gradually. In the meantime, when the slope is short, the relative error of the two safety factors is small, but with the increase of the slope height, the relative error using traditional strength reduction method increases gradually because the change of the internal stress field of the slope is not considered. Therefore, the nonlinear strength reduction method based on HB criterion can be effectively applied to the stability analysis of high rock slope.

\section{Application on southwest slope of Dagushan Open-pit Iron Mine}

\subsection{Geological conditions of Dagushan Iron Mine}

Dagushan Iron Mine is located in Anshan City, Liaoning Province, China, as shown in Figure 11. The mine is located in the edge of Qianshan Mountain and the branch of Changbai Mountain. Its landform is mainly hilly. Because the southeast is Qianshan Mountain area and the northwest is mainly plain, the terrain is low in the northwest and high in the southeast. According to the regional geological data and survey report, the strata from top to bottom in the mining area are mainly: Quaternary eluvium of Cenozoic, quartz layer of Diaoyutai formation of Qingbaikou system of Upper Proterozoic, qianmei layer of Langzishan formation 
of Liaohe Group of Lower Proterozoic, chlorite quartz sheet layer and iron quartz layer of yingtaoyuan formation of Anshan Group of Archaean. The pit of Dagushan Iron Mine is located in the west of the mining area. The mining technology is high and steep slope mining, and the open pit mining extends to the underground in a ladder shape. The southwest side of Dagushan iron mine pit is a typical high rock slope. Previous landslides were caused by sliding along the weak structural plane caused by precipitation. The annual rainy season is the most frequent period of landslide disasters.

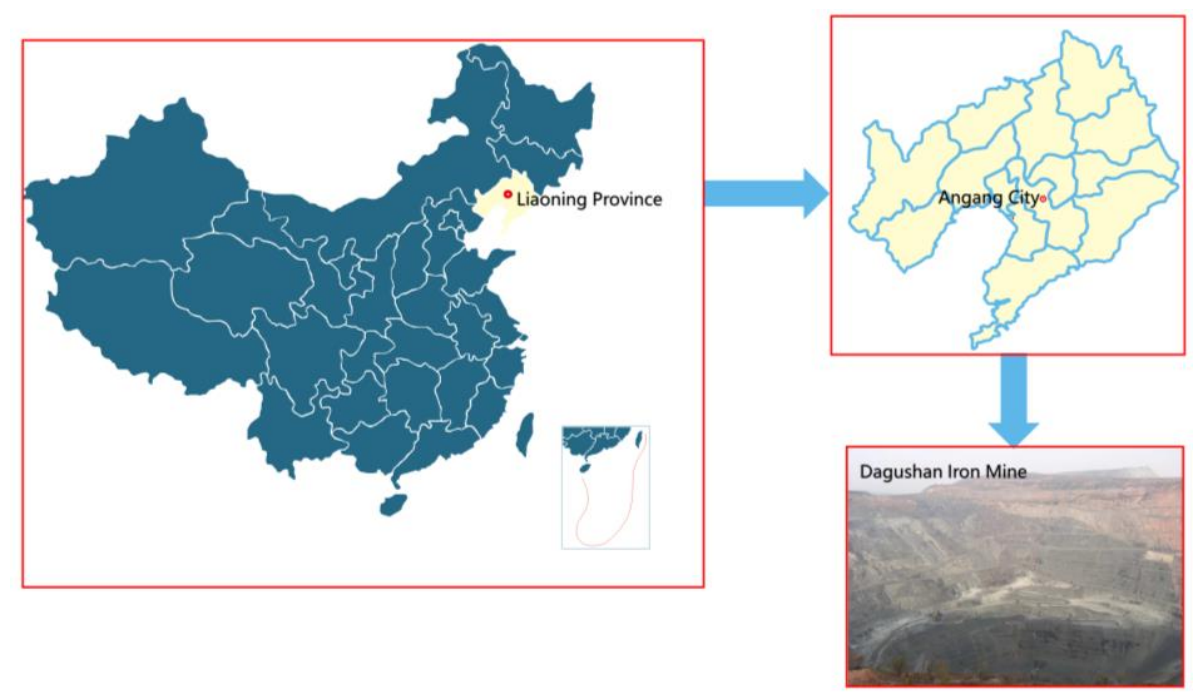

Fig. 11 Geographical location of mining area

\subsection{The establishment of geometric model}

Based on the field investigation of Dagushan Open-pit Iron Mine and the collection of relevant geological data and monitoring data, the southwest slope area is selected as the research object, which is a typical high rock slope. The main rock layers of the slope in this area are migmatite, porphyrite, granite and magnetite quartzite. The distribution of the rock layers in the section is shown in Figure 12. The stratum in this area is composed of many kinds of rock strata, and the joint fissures are relatively developed. Through communication with the site staff, there has been a small-scale slide on the slope in the area, which causes the deformation of the upper part of the slope and damages the corresponding facilities and buildings. According to the microseismic monitoring data, a large number of microseismic events occurred in this area due to rainfall.

In this work, COMSOL multiphysics multi physical field simulation software is used for numerical calculation, and Richards equation model is used for seepage field calculation. The selected calculation profile of the southwest slope of Dagushan open-pit iron mine is shown in Figure 12. The whole calculation grid area is 411500 square meters, the unit type is triangle unit, the number of units is 3245 , and the number of grid vertices is 1719 .
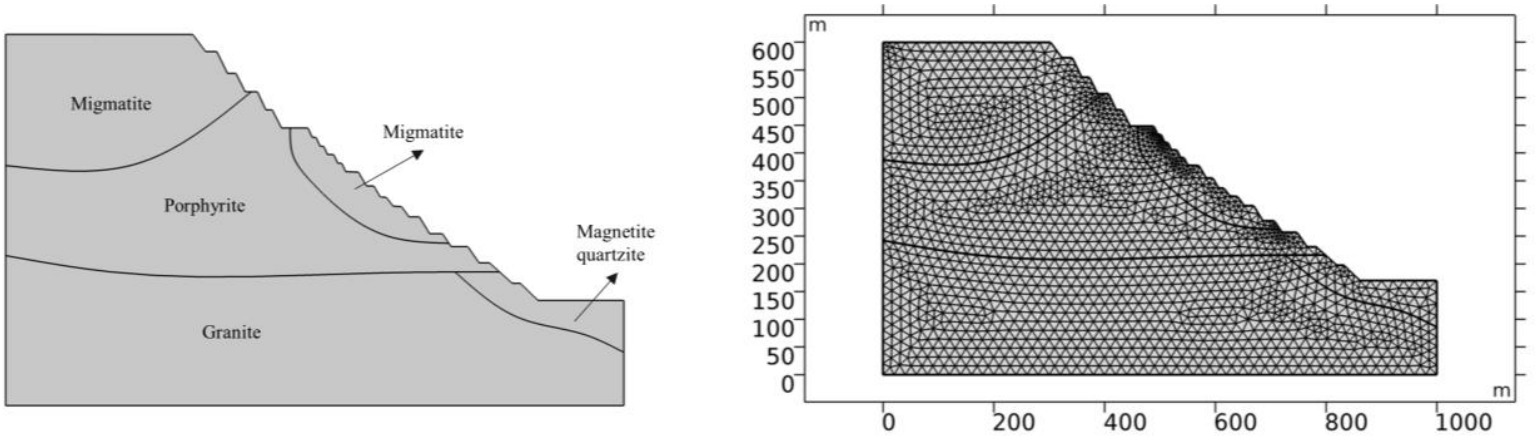
Fig. 12 Strata and Calculation model of the slope

\subsection{Initial conditions and parameters}

\subsubsection{Permeability tensor and hydraulic characteristic parameters of fractured rock mass}

Through the field sampling and investigation of the joints and fissures in the slope rock mass of Dagushan open-pit mine, and then statistical analysis, the fracture geometric parameters of the southwest slope rock mass are obtained as shown in Table 2.

Tab. 2 Fracture geometric parameters

\begin{tabular}{ccccc}
\hline \multirow{2}{*}{ Rock type } & Fracture group & $\begin{array}{c}\text { Average hydraulic } \\
\text { clearance width }(\mathrm{mm})\end{array}$ & Fissure distance $(\mathrm{m})$ & Dip angle $\left(^{\circ}\right.$ ) \\
\hline \multirow{2}{*}{ Migmatite } & 1 & 3.0 & 3.8 & 115 \\
& 2 & 2.0 & 6.7 & 48 \\
Porphyrite & 3 & 0.8 & 8.4 & 158 \\
& 1 & 4.0 & 5.2 & 121 \\
Granite & 2 & 2.0 & 7.8 & 67 \\
& 1 & 0.5 & 4.9 & 28 \\
Magnetite quartzite & 2 & 0.9 & 11.2 & 81 \\
& 1 & 0.3 & 6.0 & 113 \\
\hline
\end{tabular}

According to the fracture geometric parameters in Table 1, the equivalent permeability tensor of the corresponding rock mass is calculated by the fracture sampling measurement method, and the calculation results of the equivalent permeability tensor of each rock layer are shown in Table 3.

Tab. 3 Equivalent permeability tensor of rock mass

\begin{tabular}{ccc}
\hline Rock type & Equivalent permeability tensor $(\mathrm{m} / \mathrm{s})$ \\
\hline Migmatite & {$\left[\begin{array}{ll}1.516 \times 10^{-6} & 1.755 \times 10^{-6} \\
1.755 \times 10^{-6} & 5.312 \times 10^{-6}\end{array}\right]$} \\
Porphyrite & {$\left[\begin{array}{ll}2.794 \times 10^{-6} & 4.136 \times 10^{-6} \\
4.136 \times 10^{-6} & 8.095 \times 10^{-6}\end{array}\right]$} \\
Granite & {$\left[\begin{array}{cc}1.754 \times 10^{-8} & -1.685 \times 10^{-8} \\
-1.685 \times 10^{-8} & 5.645 \times 10^{-8}\end{array}\right]$} \\
& {$\left[\begin{array}{cc}4.544 \times 10^{-9} & 5.319 \times 10^{-9} \\
5.319 \times 10^{-9} & 1.895 \times 10^{-8}\end{array}\right]$}
\end{tabular}

\subsubsection{Mechanical parameters of rock mass}

Through field investigation and data collection, the development of joint fissures, dominant joint occurrence and structural plane distribution characteristics of slope rock mass can be obtained. According to the rock mechanics indexes obtained from various rock mechanics tests conducted before in Dagushan, the calculation parameters of slope stability are obtained based on HB strength theory. The adopted values of relevant calculation parameters are shown in Table 4.

Tab. 4 Parameters for stability calculation

\begin{tabular}{cccccccc}
\hline \multirow{2}{*}{ Rock type } & Density & Uniaxial & Elastic & Poisson's & \multicolumn{2}{c}{ Hoek-Brown strength parameters } \\
& $\left(\mathrm{kg} / \mathrm{m}^{3}\right)$ & compression stress & modulus & ratio & $G S I$ & $D$ & $m_{i}$ \\
\hline
\end{tabular}




\begin{tabular}{cccccccc}
\multicolumn{7}{c}{$(\mathrm{MPa})$} & $(\mathrm{GPa})$ \\
\hline Migmatite & 2600 & 62.29 & 38.72 & 0.33 & 35 & 0.9 & 12 \\
Porphyrite & 2700 & 79.61 & 41.19 & 0.28 & 45 & 0.8 & 15 \\
Granite & 2700 & 83.55 & 54.13 & 0.20 & 50 & 0 & 18 \\
Magnetite & & & & & 0.9 & 20 \\
quartzite & 3000 & 109.32 & 77.42 & 0.11 & 50 & 0.9 \\
\hline
\end{tabular}

\subsubsection{Rainfall schemes}

The change of rainfall conditions will affect the distribution of seepage field in the rock slope, and the seepage field will affect the stability of the slope. In this work, we will study the change of slope seepage field and then calculate the change of slope stability under different rainfall conditions. According to the relevant meteorological data, the daily maximum precipitation of Dagushan open-pit mining area is $236.8 \mathrm{~mm}$. On this basis, to analyze the influence of rainfall intensity, rainfall duration and total rainfall on slope stability, we designed four different schemes as shown in Table 5.

Table 5 Rainfall Schemes

\begin{tabular}{ccccc}
\hline Scheme & Scheme I & Scheme II & Scheme III & Scheme IV \\
\hline Rainfall intensity (mm/h) & 10 & 10 & 20 & 40 \\
Rainfall duration (h) & 12 & 24 & 12 & 6 \\
Duration after rain stops (h) & 24 & 24 & 24 & 24 \\
Total rainfall (mm) & 120 & 240 & 240 & 240 \\
\hline
\end{tabular}

\subsubsection{Initial conditions}

The boundary of the left and right sides of the slope numerical model is set with a given water head boundary, the water head is equal to the height of the groundwater level at the boundary. In the meantime, the bottom boundary is set as flux boundary due to hydraulic conduction. The boundary conditions of the slope surface are set according to the rainfall intensity: when the rainfall intensity is less than the saturated permeability coefficient of the slope rock, the surface boundary is set as a given flow boundary, and the flow size is rainfall intensity; if not, the boundary is set as the given water head boundary, and the surface runoff formed at this time is relatively small, so the water head height is the elevation of this place, that is, the surface of the slope is the zero-pressure surface.

The initial conditions are obtained from the hydrogeological conditions of the region according to the back analysis of the stable seepage field, and the pore water pressure distribution in line with the actual situation is obtained by continuously adjusting the flow flux at the bottom boundary. The calculated initial pore water pressure distribution is shown in Figure 13, in which the blue solid line is the groundwater level line, the pore water pressure in the area below the groundwater level line is positive, and the pore water pressure in the area below the groundwater level line is negative, and the negative value represents the matrix suction in the area. 


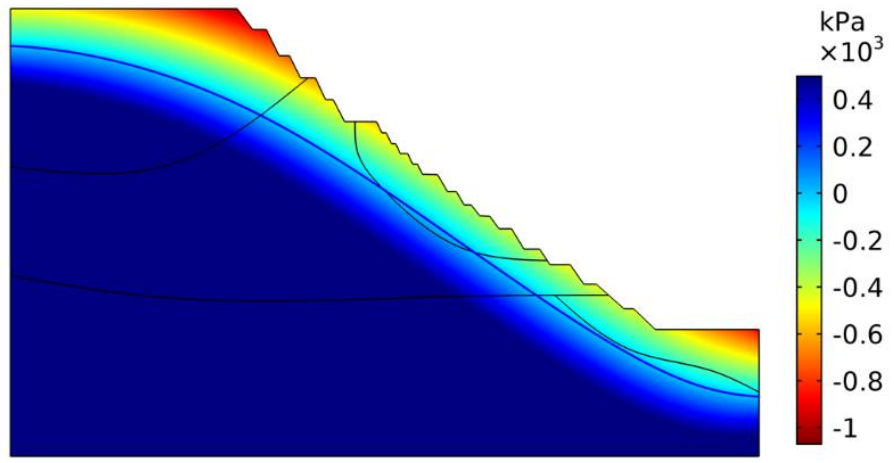

Fig. 13 Initial pore water pressure and groundwater level

\section{Numerical calculation and analysis of high rock slope under rainfall}

\section{infiltration}

The proposed nonlinear strength reduction method based on Hoek Brown criterion is used to calculate the safety factor of slope. The minimum principal stress in the slope is calculated so that the cohesion and internal friction angle of the slope rock mass can be obtained. The pore water pressure of slope at the initial time of rainfall $(0 \mathrm{~h})$ is substituted into the calculation model, and the strength reduction calculation is carried out for the cohesion and internal friction angle calculated above. Based on the non convergence of calculation, the factor of safety (FOS) at the initial time of rainfall is calculated to be 1.544. The distribution of plastic strain and total displacement at the initial time are shown in Figure 14.

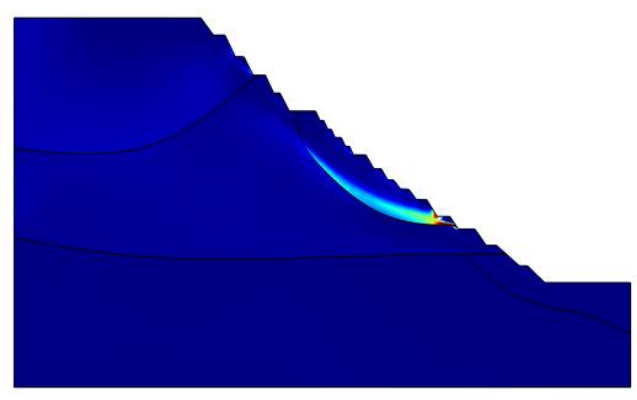

(a) Plastic strain

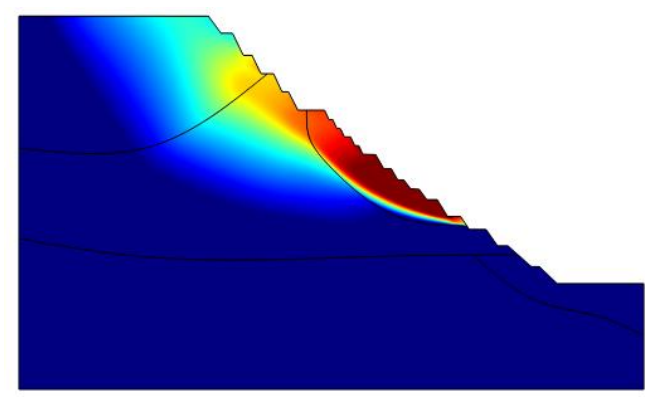

(b) Total displacement

Fig. 14 Distribution of plastic strain and total displacement at the initial time

\subsection{Influence of rainfall duration on slope stability}

The rainfall intensity of Scheme I and Scheme II is $10 \mathrm{~mm} / \mathrm{h}$. The rainfall duration of Scheme I is $12 \mathrm{~h}$, the rainfall duration of Scheme II is $24 \mathrm{~h}$, and the calculated duration after the rainfall stops is $24 \mathrm{~h}$. According to the calculation results of the slope safety factor of Scheme I and Scheme II, the change diagram of the slope safety factor with time can be obtained, as shown in Figure 15. 


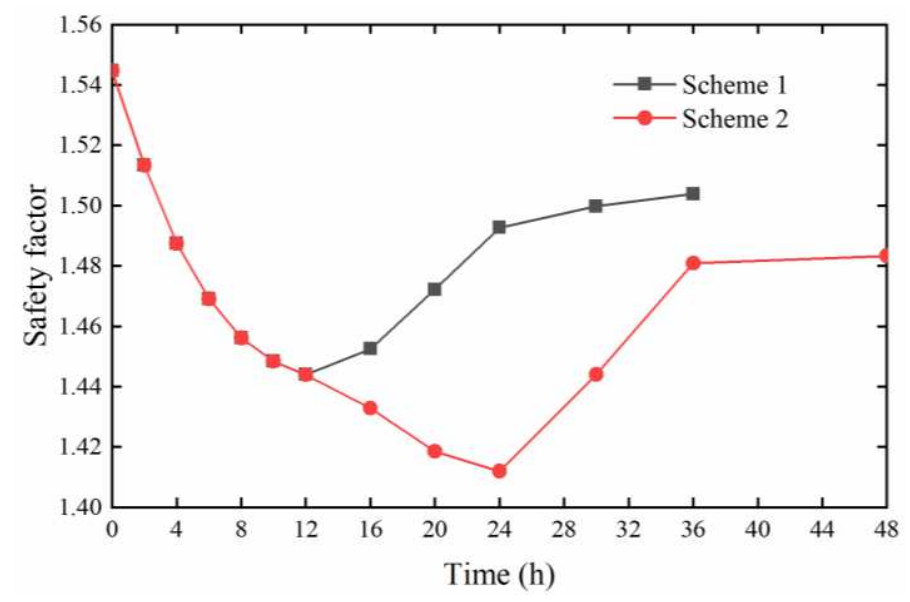

Fig. 15 Slope safety factor with time (Scheme I and Scheme II)

It can be seen from Figure 15 that the safety factor of the slope is 1.544 at the beginning of the rainfall. When the rainfall intensity remains unchanged, the safety factor decreases gradually with the increase of rainfall duration. The safety factor is 1.443 and decreases by 0.101 in 12 hours of rainfall. The rainfall of Scheme I stops at this time. Then the safety factor starts to rise gradually, and it rises to 1.504 at 24 hours after stopping the rainfall. This is because the increment of water load is large, the pore water pressure is increasing and the matrix suction is decreasing when it rains. It leads the safety factor of slope to decrease. When the rainfall stops, there is no rainwater supply, and the previously infiltrated rainwater continues to infiltrate under the effect of gravity. Then the pore water pressure on the upper part of the slope surface gradually decreases. It leads the safety factor to increase. But because the dissipation speed of pore water pressure is relatively slow, the safety factor gradually tends to be stable but less than the safety factor at the initial time.

In Scheme II, the rainfall continues for 24 hours and the safety factor decreases to 1.412 at 24 hours after raining. After 16 hours, the decrease rate of safety factor increases, which is due to the formation of transient saturated zone (TSZ) on the surface of the slope. TSZ has a great impact on the stability of the slope. After the rainfall stops, the safety factor of Scheme II rises gradually to 1.483 at 24 hours which is smaller than the safety factor of Scheme I at 24 hours after rain.

\subsection{Influence of rainfall intensity on slope stability}

(1) The same rainfall duration

The rainfall intensity of Scheme I is $10 \mathrm{~mm} / \mathrm{h}$, and that of Scheme II is $20 \mathrm{~mm} / \mathrm{h}$. The rainfall duration of the two schemes is the same, both of them are $12 \mathrm{~h}$, and the calculated time length after the rainfall stops is $24 \mathrm{~h}$. According to the calculation results of the slope safety factor of Scheme I and Scheme III, the change diagram of the slope safety factor with time can be obtained, as shown in Figure 16. 


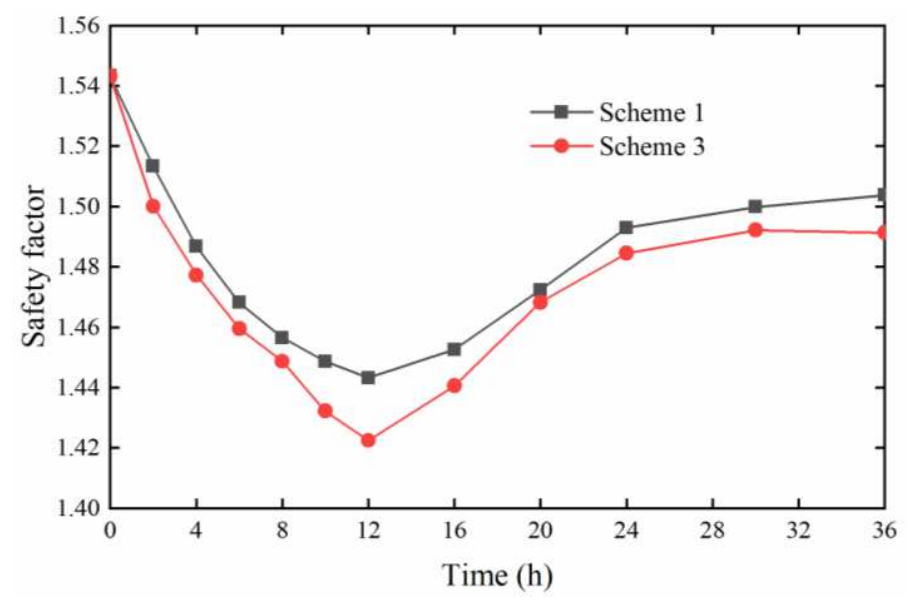

Fig. 16 Slope safety factor with time (Scheme I and Scheme III)

It can be seen from Figure 16 that the changes in safety factor of Scheme I and Scheme III are similar, both of them reach the lowest level in 12 hours of continuous rainfall, and the safety factor of Scheme III is lower than that Scheme I. In the meantime, in the duration of rainfall and the time after the rainfall stopped, the safety factor of Scheme III is always lower than that of Scheme I. For Scheme III, the decrease rate of safety factor increases after 8 hours, mainly because the formation of TSZ has a greater impact on slope stability. Overall, the comparison of Scheme I and Scheme III shows that when the rainfall duration is the same, the greater the rainfall intensity is, the lower the slope safety factor is.

(2) The same total rainfall

The total rainfall of Scheme II, Scheme III and Scheme IV is $240 \mathrm{~mm}$, the rainfall intensity is respectively $10 \mathrm{~mm} / \mathrm{h}, 20 \mathrm{~mm} / \mathrm{h}$ and $40 \mathrm{~mm} / \mathrm{h}$, the duration is respectively 24 hours, 12 hours and 6 hours, and the calculated duration after the rainfall stops is 24 hours. According to the calculation results of the slope safety factor of Scheme II, Scheme III and Scheme IV, the change diagram of the slope safety factor with time can be obtained, as shown in Figure 17.

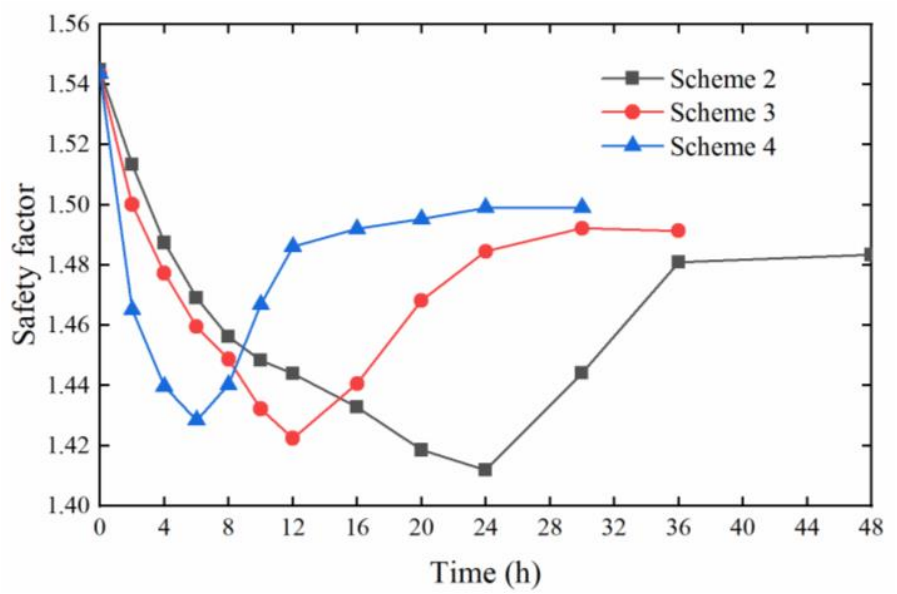

Fig. 17 Slope safety factor with time (Scheme II, Scheme III and Scheme IV)

It can be seen from Figure 17 that the safety factors of the three schemes gradually decrease with the continuous rainfall. All of the safety factors become the smallest at the end of the rainfall, and then they gradually recover and increase in a period of time after the rainfall stops. In the process of continuous rainfall, the safety factor of Scheme IV decreases the fastest, followed by Scheme III. This is due to the large rainfall in a short time, the large increment of water load in the slope and the large change of safety factor. Although the total rainfall of the three schemes is equal, the minimum safety factors of the three schemes are different. 
The minimum safety factor of Scheme IV is the largest, Scheme III is the second, and Scheme II is the smallest. When the rainfall stops (24h), the safety factor of Scheme 4 is also the largest among the three schemes. The main reason for this phenomenon is that for heavy rainfall in a short time, although the water load increment is large, due to the short infiltration time of rainwater into the slope, the shallow hydraulic conduction depth, and some rainwater will form surface runoff. Although the rainfall intensity for a long time is smaller, the rainwater has sufficient time to continuously infiltrate, the infiltration depth into the slope is greater, the area of rainfall infiltration is larger, and the impact on slope stability is greater. The comprehensive analysis of the three schemes shows that when the total rainfall is the same, the impact of short-term heavy rainfall on slope stability is less than long-term ordinary rainfall, that is, the longer the rainfall duration, the greater the impact on slope stability.

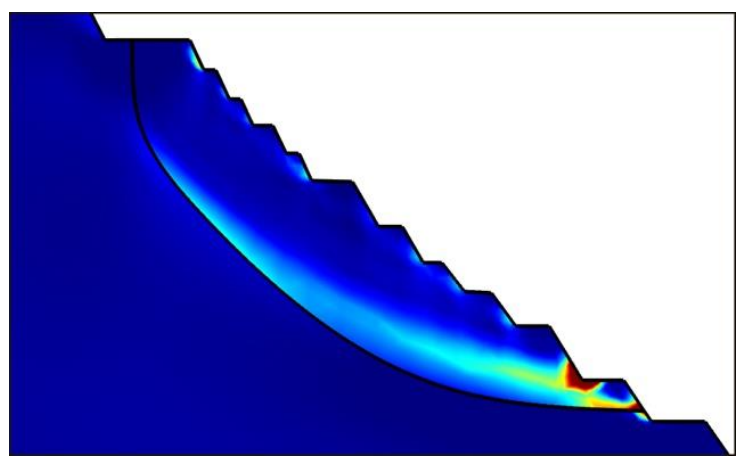

(a) Scheme I

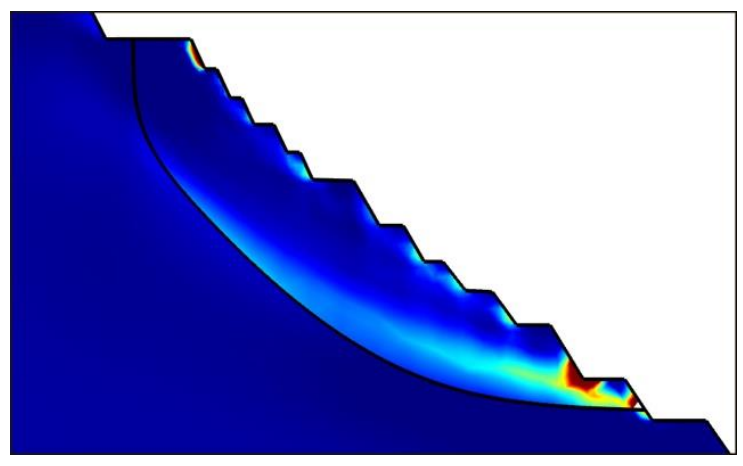

(c) Scheme III

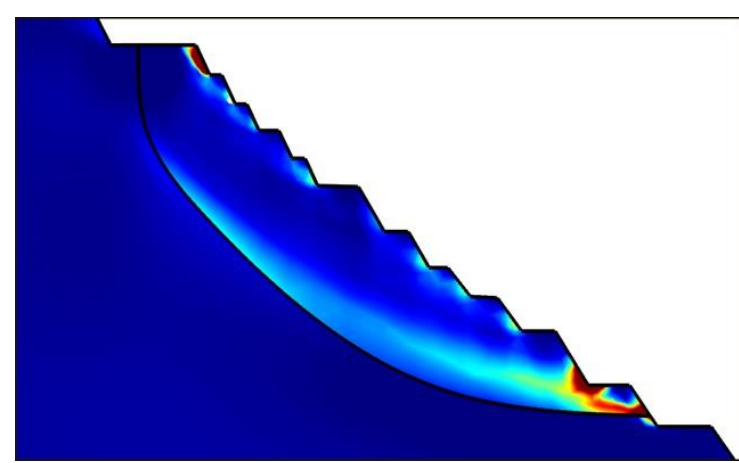

(b) Scheme II

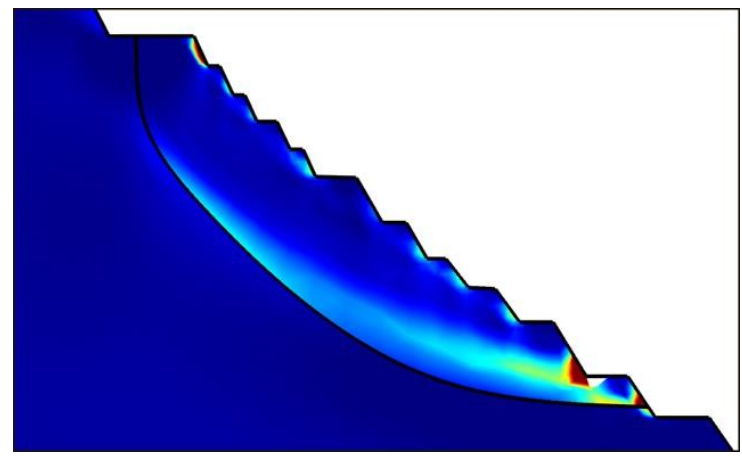

(d) Scheme IV

Fig.18 Distribution of plastic strain at the end of rainfall

At the end of rainfall, the plastic strain distribution of slope are shown in Figure 18. In the figure, (a), (b), (c) and (d) represent the plastic strain of Scheme I at $12 \mathrm{~h}$, Scheme II at $24 \mathrm{~h}$, Scheme III at $12 \mathrm{~h}$ and Scheme IV at $6 \mathrm{~h}$ respectively. Comparing Figure 14 with Figure 18, it can be seen that the overall plastic zone does not change much, but there is a through plastic zone on some single steps of the slope, especially in Scheme II, which shows that the impact of rainfall infiltration on the stability of some single steps is greater than that of the overall slope. In the process of rainfall, the pore water pressure on the slope surface increases continuously, forming a transient saturation zone, and the rock mass of some steps reaches a transient saturation state. At this time, the water content of rock mass increases, the shear strength decreases, and the sliding force increases, resulting in a significant reduction in the stability of some single steps. This situation often occurs in practical engineering, and long-term rainfall could cause the deformation and failure of a single step or several adjacent steps of the slope.

As mentioned above, a comparative analysis of the four schemes reveals that the FOS will decrease 
with the increase of rainfall duration. Under the same rainfall duration, the higher the rainfall intensity, the lower the FOS of slope. And under the same total rainfall, the effect of short-term rainstorm on slope stability is smaller than that of long-term ordinary rainfall, and the longer the duration of rainfall, the greater the impact on slope stability.

\section{Conclusion}

In this work, a new nonlinear strength reduction method based on Hoek-Brown criterion is proposed for the high ground stress of high rock slope, which is preliminarily verified by COMSOL Multiphysics software. On this basis, taking the southwest slope of Dagushan Mine as an example, the rock slope of openpit mine under different rainfall conditions is simulated, and the following conclusions can be obtained:

(1) Considering the characteristics of high rock slope with high ground stress, based on Hoek-Brown criterion, the instantaneous cohesion and internal friction angle under different principal stresses are derived, based on which a nonlinear strength reduction method is proposed for high rock slope.

(2) Based on the proposed nonlinear strength reduction method, the stability of a typical high rock slope is analyzed by COMSOL Multiphysics software. The comparison with the traditional strength reduction method shows that calculation results of the proposed method are more in line with the failure characteristics of high rock slope.

(3) When the slope height is small, the difference of FOS calculated by the traditional reduction method and the reduction method proposed in this work is small. However, with the increase of slope height, the traditional reduction method overestimates the slope stability because it does not consider the change of slope internal stress field. Therefore, the proposed nonlinear strength reduction method is more suitable for FOS calculation of high rock slope.

(4) Through the numerical simulation of open-pit mine slope under rainfall, the FOS of slope under different rainfall conditions are calculated according to the proposed strength reduction method. By analyzing the evolution laws of safety factor, it is found that the formation of transient saturation zone and long-term rainfall have a great impact on slope stability.

\section{Acknowledgments}

This study was supported by the National Natural Science Foundation of China (nos. 61973305), the Beijing Science and Technology Planning Project (nos. Z201100004520015) and the Natural Science Foundation of Liaoning Province (nos. 2020-KF-22-02).

\section{Data availability}

The data that support the findings of this study are available from the corresponding author upon reasonable request.

\section{References}

[1] Huang R. Geodynamical process and stability control of high rock slope development[J]. Yanshilixue Yu Gongcheng Xuebao/Chinese Journal of Rock Mechanics and Engineering, 2008, 27(8): $1525-1544$.

[2] Sarma S K. Stability analysis of embankments and slope[J]. Journal of Geotechnical Engineering, 1979, 105: 1511-1524.

[3] Chen ZY, Morgenstern N R. Extensions to the generalized method of slices for stability analysis[J]. 
Canadian Geotechnical Journal, 2011, 20(1): 104-119.

[4]Chen Z Y, Mi H L, Wang X G. Limit equilibrium method for three-dimensional analysis of slope stability[J]. Chinese Journal of Geotechnical Engineering, 2001, 23(5): 525-529.

[5] Zou J Z, David J W. Search for critical slip surface based on finite element method[J]. Canadian Geotechnical Journal, 1995, 32(2): 233-246.

[6] Duncan J M . State of the art: limit equilibrium and finite-element analysis of slopes[J]. Journal of Geotechnical Engineering, 1996, 123(7): 577-596.

[7] Xu J, Pan Q, Yang X L, et al. Stability charts for rock slopes subjected to water drawdown based on the modified nonlinear Hoek-Brown failure criterion[J]. International Journal of Geomechanics, 2018, 18(1): 04017133.

[8] Wang H, Y Yang, Sun G, et al. A stability analysis of rock slopes using a nonlinear strength reduction numerical manifold method[J]. Computers and Geotechnics, 2021, 129: 103864.

[9] Rezaur R B, Rahardjo H, Leong E C. Spatial and temporal variability of pore-water pressures in residual soil slopes in a tropical climate[J]. Earth Surface Processes and Landforms, 2002, 27(3): 317-338.

[10] Alonso E E, Gens A, Delahaye C H . Influence of rainfall on the deformation and stability of a slope in overconsolidated clays: a case study[J]. Hydrogeology Journal, 2003, 11(1): 174-192.

[11] Zhang N, Zhang B, Liu L B, et al. Numerical analysis of slope stability under the effect of rainfall infiltration[J]. Journal of Mining Science, 2017(2): 26-34.

[12] Rahimi A, Rahardjo H, Leong E C. Effect of hydraulic properties of soil on rainfall-induced slope failure[J]. Engineering Geology, 2010, 114(3-4): 135-143.

[13] Ahour M, Hataf N, Azar E. A mathematical model based on artificial neural networks to predict the stability of rock slopes using the generalized Hoek-Brown failure criterion[J]. Geotechnical and Geological Engineering, 2020, 38(9).

[14] You T, Dai Z, Lu C, et al. A rounding approach the singular surface of Hoek-Brown criterion and its strength reduction technique[J]. Yanshilixue Yu Gongcheng Xuebao/Chinese Journal of Rock Mechanics and Engineering, 2017, 36(7):1659-1669.

[15] Fu W, Yi L. Non-linear shear strength reduction technique in slope stability calculation[J]. Computers \& Geotechnics, 2010, 37(3):288-298.

[16] Zhao L. Seismic stability quasi-static analysis of homogeneous rock slopes with Hoek-Brown failure criterion[J]. China Civil Engineering Journal, 2010, 43:541-547.

[17] Chowdhury R N. Slope analysis. Developments in geotechnical engineering, vol 22: Chowdhury, R N Amsterdam: Elsevier, 1978, 422P[J]. International Journal of Rock Mechanics \& Mining Sciences \& Geomechanics Abstracts, 1980, 17(2):34.

[18] Shen J, Karakus M, Xu C. Direct expressions for linearization of shear strength envelopes given by the Generalized Hoek-Brown criterion using genetic programming[J]. Computers \& Geotechnics, 2012, 44(6):139-146.

[19] Sun C, Chai J, Xu Z, et al. Stability charts for rock slopes based on the method of reduction of Hoek-Brown strength[J]. Yanshilixue Yu Gongcheng Xuebao/Chinese Journal of Rock Mechanics and Engineering, 2018, 37(4):838-851.

[20] Liao Y, Zeng X G, Fu W X, et al. Linearization method of non-linear strength of Hoek-Brown rock mass[J]. Zhongnan Daxue Xuebao (Ziran Kexue Ban)/Journal of Central South University (Science and Technology), 2012, 43(12):4902-4911.

[21] Yuan W, Li J, Li Z, et al. A strength reduction method based on the Generalized Hoek-Brown 
(GHB) criterion for rock slope stability analysis[J]. Computers and Geotechnics, 2020, 117. https: //doi.org/10.1016/j.compgeo.2019.103240.

[22] Saada Z , Maghous S , Garnier D . Seismic bearing capacity of shallow foundations near rock slopes using the generalized Hoek-Brown criterion[J]. International Journal for Numerical \& Analytical Methods in Geomechanics, 2011, 35(6):724-748.

[23] Wu S C , Jin A B , Gao Y T . Numerical simulation analysis on strength reduction for slope of jointed rock masses based on gereralized Hoek-Brown failure criterion[J]. Chinese Journal of Geotechnical Engineering, 2006, 28(11): 1975-1980.

[24] Chen C F , Weng J L . Strength reduction method based on generalized Hoek-Brown criterion for slope stability analysis[J]. The Chinese Journal of Geological Hazard and Control, 2010. https: //doi.org/10.1016/S1876-3804(11)60004-9

[25]Chun, B S, Lee J M, Choi H S, et al. Numerical Study on the Stability Analyses of Rock Slopes considering Non-linear Characteristics of Hoek-Brown Failure Criterion[J]. Journal of the Korean GeoEnvironmental Society, 2003, 4(2): 77-91.

[26] Yuan W, Li X C, Wang W, et al. Study on strength reduction method based on double reduction parameters[J]. Rock and Soil Mechanics, 2016, 37(8): 2222-2230. https: //doi.org/10.16285/j.rsm.2016.08.013.

[27] Nekouei A M , Ahangari K . Validation of Hoek-Brown failure criterion charts for rock slopes[J]. International Journal of Mining Science and Technology, 2013(06): 805-808.

[28] Liu L, Yao L, Chen J , et al. Rock slope stability analysis based on hoek-brown failure criterion[J]. Chinese Journal of Rock Mechanics \& Engineering, 2010, 29: 2879-2886.

[29] Xu J , Yang X . Seismic stability analysis and charts of a 3D rock slope in Hoek-Brown media[J]. International Journal of Rock Mechanics and Mining Sciences, 2018, 112: 64-76.

[30] Hammah R E, Yacoub T E, Corkum B, Curran JH. The shear strength reduction method for the generalized Hoek-Brown criterion. Proceedings of the 40th US symposium on rock mechanics, Alaska Rocks 2005, Anchorage, Alaska. 2005.

[31] Thomas B, Radu S, Regina A K, Pieter AV. A Hoek-Brown criterion with intrinsic material strength factorization.International Journal of Rock Mechanics and Mining. Science 2008;45(2):210-22.

[32] Wu S , Xiong L, Zhang S . Strength Reduction Method for Slope Stability Analysis Based on a Dual Factoring Strategy[J]. International Journal of Geomechanics, 2018, 18(10): 04018123.1-04018123.14.

[33] Li A J , Merifield R S , Lyamin A V . Stability charts for rock slopes based on the Hoek-Brown failure criterion[J]. International Journal of Rock Mechanics \& Mining Sciences, 2008, 45(5):689-700.

[34]. Sun C W, Chai J R, Xu Z G, et al. Stability charts for rock mass slopes based on the Hoek-Brown strength reduction technique[J]. Engineering Geology, 2016, 214: 94-106.

[35] Benz T, Schwab R , Kauther R A, et al. A Hoek-Brown criterion with intrinsic material strength factorization[J]. International Journal of Rock Mechanics \& Mining Sciences, 2008, 45(2):210-222.

[36] Yang X L, Yin J H . Slope equivalent Mohr-Coulomb strength parameters for rock masses satisfying the Hoek-Brown criterion[J]. Rock Mechanics \& Rock Engineering, 2010, 43(4):505-511.

[37] Hoek E, Brown E T . Empirical strength criterion for rock masses[J]. Journal of the Geotechnical Engineering Division, 1980, 106(15715):1013-1035.

[38] Zheng H, Sun G H, Liu D F. A practical procedure for searching critical slip surfaces of slopes based on the strength reduction technique. Comput Geotech 2009, 36(1-2): 1-5.

[39] Zhao S Y, Zheng Y R and Deng W D. Stability analysis of jointed rock slope by strength reduction 
method FEM [J]. Chinese Journal of Rock Mechanics and Engineering, 2003 (02): 254-260.

[40] Zong Q B, Xu W Y. Stability analysis of excavating rock slope using generalized Hoek-Brown failure criterion [J]. Rock and Soil Mechanics, 2008 (11): 3071-3076.

[41] Song Q, Yan E C, Mao W, et al. Determination of Shear Strength Reduction Factor for generalized Hoek-Brown criterion [J]. Chinese Journal of Rock Mechanics and Engineering, 2012, 31 (01): 106-112.

[42] Zhang L, Yang D, Chen Z, et al. Deformation and failure characteristics of sandstone under uniaxial compression using distributed fiber optic strain sensing[J]. Journal of Rock Mechanics and Geotechnical Engineering, 2020, 12(5): 1046-1055.

[43] Zhuo L, He J D, Xie H Q, et al. Study of New Method to Determine Strength Parameters of Rock Material based on Hoek-Brown Criterion [J]. Chinese Journal of Rock Mechanics and Engineering, 2015 (s1): 2773-2782.

[44] Zeng Q , Ma P , Liu T . Approximate solution of the radial stress at the generalized Hoek-Brown elastic-plastic zone interface for surrounding rocks of circular openings[J]. Tumu Gongcheng Xuebao/China Civil Engineering Journal, 2011, 44(12):85-92.

[45] Ma L J, Yang F, Wang M Y, et al. Generalized Hoek-Brown dynamic strength criterion incorporating strain rate effect[J]. Yantu Lixue/Rock and Soil Mechanics, 2017, 38: 27-32. 